\title{
Structure-mechanical property relationship in Hot-Dip Galvanized S355k2+N steel plates
}

\author{
Wiem Toumi Ajimi ${ }^{1, a}{ }^{*}$, Delphine Retraint ${ }^{1, b}$ and Guillaume Montay ${ }^{1, c}$ \\ ${ }^{1}$ ICD-Lasmis, Université de Technologie de Troyes (UTT), CNRS UMR 6279, 12 Rue Marie Curie, \\ CS 42060, 10004 Troyes, France

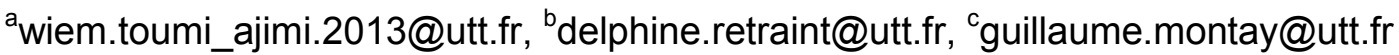

Keywords: Structural steel, galvanization, residual stress, incremental hole drilling method, microstructure and texture formation.

\begin{abstract}
The aim of this study is the characterization of hot-dip galvanized S355K2+N steel plates used as components for engineering civil structures. Two thin zinc coatings with a thickness of $145+/-14 \mu \mathrm{m}$ and $329+/-23 \mu \mathrm{m}$, were developed at the surface of the plates. Several experimental techniques were performed to study the microstructure, the chemical composition at the surface of the galvanized plates. The residual stress field was also evaluated in the coatings and the top surface of the plates using the incremental hole drilling method, in the rolling and the transverse directions. The results show the presence of tensile stresses and compressive stresses respectively in the coating and the substrate.
\end{abstract}

\section{Introduction}

Corrosion protection is an important step in the manufacturing of steel structures such as thermal spraying, electroplating and Hot-Dip Galvanizing (HDG). HDG treatment is one of the protection techniques of greater importance which generates a coating of an iron-zinc alloy by immersion in a bath of molten zinc at $450^{\circ} \mathrm{C}$. Four intermetallic layers: zeta, delta, gamma and eta are formed. The kinetics phase formation and the thickness of the coating are influenced by the content of the silicon and the phosphorus in the substrate [1] as well as the temperature and the time of the immersion in the bath [2]. The hardness of each phase decreases from the Fe/coating interface to the surface with the decreasing of the Fe proportion.

Most galvannealing research focuses on the identification of the chemical composition, the influence of the hold time [3], the alloying elements [4], the resistance of the coating to the corrosion or to the fatigue [5]. However, residual stresses, generated by Hot-dip Galvanizing treatment and their influence on mechanical behavior are seldom studied. Most coatings obtained by deposition techniques (electroplating, DLC, etc) are usually under high compressive stresses [6]. Tensile stresses generated in the HDG coating are generally due to the superposition of intrinsic and thermal stresses [7]. Many techniques can lead to the evaluation of the residual stress such as the incremental hole drilling technique. This method, involves the drilling in a series of small steps, is able to determine stress profiles and gradients in different directions. Thus, quantitative approximation of residual stresses is necessary for the safe performance of steel structures.

\section{Experimental methods}

The specific composition of the as-received S355K2+N steel plate $\left(400 \times 300 \times 10 \mathrm{~mm}^{3}\right)$ and the zinc bath are respectively given in Table 1 and Table 2 . The plate was cut in three sheet samples $\left(350 \times 100 \times 10 \mathrm{~mm}^{3}\right)$. Two samples, $\mathrm{A}$ and $\mathrm{B}$, were considered in order to be galvanized according to standard NF ENI ISO 1461 , at $450^{\circ} \mathrm{C}$ with a holding time of 3 min for specimen A and 10 min for specimen B. The coating thickness obtained was, respectively, $145+/-14 \mu \mathrm{m}$ and $329+/-23 \mu \mathrm{m}$ for A and $\mathrm{B}$. These thickness values correspond to an average of 45 measurements using an Elcomter Device used for the estimation of the coating thickness. 
Table 1. Chemical composition of steel substrate [wt.\%].

\begin{tabular}{|l|c|c|c|c|c|c|c|}
\hline $\begin{array}{l}\text { S355K2+N_NF } \\
\text { EN 10025- }\end{array}$ & $\mathrm{C}$ & $\mathrm{Si}$ & $\mathrm{Mn}$ & $\mathrm{P}$ & $\mathrm{S}$ & $\mathrm{Cu}$ & $\mathrm{Fe}$ \\
\cline { 2 - 8 } $2 / 2004$ & 0,2 & 0,55 & 1,6 & 0,025 & 0,025 & 0,55 & 98,8 \\
\hline
\end{tabular}

Table 2. Chemical composition of zinc bath [wt.\%].

\begin{tabular}{|c|c|c|c|c|c|}
\hline $\mathrm{Al}$ & $\mathrm{Cu}$ & $\mathrm{Fe}$ & $\mathrm{Pb}$ & $\mathrm{Sn}$ & $\mathrm{Zn}$ \\
\hline 0,004 & 0,008 & 0,02 & 0,906 & 0,013 & 99,049 \\
\hline
\end{tabular}

Optical and scanning electron microscopes were used for metallographic study on the top surface and along the cross-section of the coating and the substrate. Samples were mechanically polished with successively $600,800,1200,2400 \mathrm{SiC}$ papers and finished with $6 \mu \mathrm{m}$ and $1 \mu \mathrm{m}$ diamond suspension. The polishing with SiC paper was carried out under ethanol because of the fragility of the zinc towards water. Finally, the samples were etched with an ethanolic $3 \mathrm{wt} \%$ nitric acid solution (Nital). It was then possible to determine the composition of both coatings using energy dispersive X-ray spectrometry (EDX).

Evaluation of the residual stress was carried out using the hole drilling method with a $2 \mathrm{~mm}$ diameter drill. Increments adapted to the thickness of the different intermetallic layers of the coating have been selected. The deformations were measured after each depth increment using CEA-06$062 \mathrm{UL}-120$ strain gage rosettes. The elastic properties $(\mathrm{E}, \mathrm{v}=0,3)$ of the different layers [8] and the substrate have been taken into account for the evaluation of the residual stress field employing the finite elements method [9], see Table 3. Gamma layer was neglected in this study because of its very low thickness.

Table 3. Young Modulus of intermetallic layers [8].

\begin{tabular}{|l|c|c|c|c|c|}
\cline { 2 - 6 } \multicolumn{1}{c|}{} & Iron & Gamma & Delta & Zeta & Eta \\
\hline Young Modulus [GPa] & 210 & - & 140 & 117 & 75 \\
\hline
\end{tabular}

\section{Results and discussion}

Structural, morphological properties of intermetallic layers. Optical images of the surface of the HDG samples are shown in Fig.1 and display bright and dark areas. Some studies have related these areas to the solidification of the zinc [10]; the solutes are rejected to the grain boundaries leaving the surface relatively pure and bright when dendrites grow parallel to the plate plane. However, when the basal plane is inclined, the growth direction and the rejection of the solutes are towards the coating surface, leading then to dark areas.

Large grains called spangles or flowery patterns have been observed, as shown in Fig. 1. M. Dutta et al [11] have mentioned that lead $(\mathrm{Pb})$, in the bath, is known to contribute to spangle formation.
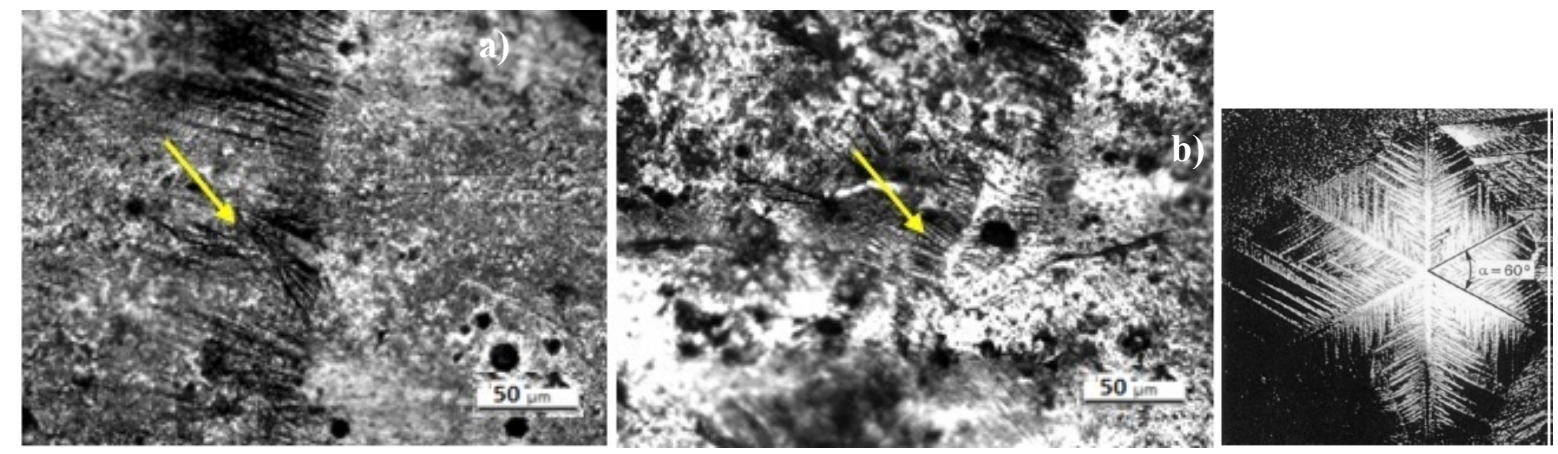

Fig.1. Spangle structure at the surface, a) samples A and B, b) clear spangle structure from literature [13]. 
Metallographic observations of the cross-sections of the two samples A and B are shown in Fig. 2 and illustrate the presence of different layers due to different diffusion kinetics of iron in the zinc layer: gamma, delta, zeta and eta layers can be distinguished.

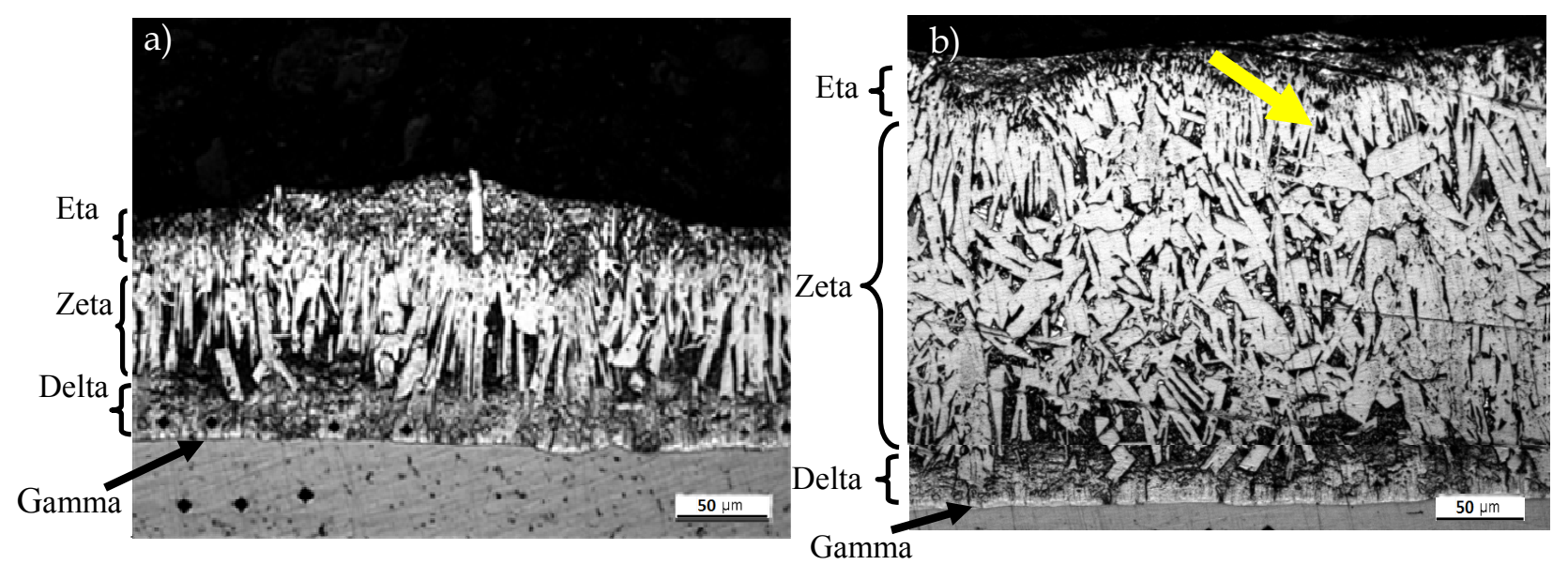

Fig. 2. Metallographic observations of iron-zinc alloy layers: a) sample A, b) sample B. (An arrow, in Fig.2-b, to indicate the presence of fine grains).

Chemical composition and the thickness of intermetallic-layers are presented in Table 4.

Table 4. Characteristics of intermetallic layers of samples A and B.

\begin{tabular}{|c|c|c|c|c|c|c|}
\hline \multirow[b]{2}{*}{ Fe-Zn layers } & \multirow[b]{2}{*}{ Structure } & \multicolumn{2}{|c|}{ Thickness $[\mu \mathrm{m}]$} & \multicolumn{2}{|c|}{$\% \mathrm{Zn}[\mathrm{wt} . \%]$} & \multirow{2}{*}{$\begin{array}{l}\text { \% } \mathrm{Zn}[\mathrm{wt} . \%] \\
\text { from } \\
\text { literature [2] }\end{array}$} \\
\hline & & $\mathrm{A}(145+/-14)$ & $\mathrm{B}(329+/-23)$ & $\mathrm{A}$ & B & \\
\hline $\operatorname{Eta}(\mathrm{Zn}(\mathrm{Fe}))$ & $\begin{array}{l}\text { Hexagonal } \\
\text { close packed }\end{array}$ & $20-35$ & $30-40$ & - & 94,31 & $98-100$ \\
\hline Zeta $\left(\mathrm{FeZn}_{13}\right)$ & $\begin{array}{l}\text { Monoclinic } \\
\text { (columnar) }\end{array}$ & $70-90$ & $200-270$ & 92,84 & 93,03 & $92-96$ \\
\hline $\begin{array}{l}\text { Delta } \\
\left(\mathrm{FeZn}_{7}\right) /\left(\mathrm{FeZn}_{10}\right)\end{array}$ & $\begin{array}{l}\text { Hexagonal } \\
\text { (columnar) }\end{array}$ & $20-35$ & $30-40$ & 91,7 & 90,97 & $90-94$ \\
\hline $\begin{array}{l}\text { Gamma } \\
\left(\mathrm{Fe}_{3} \mathrm{Zn}_{10}\right) /\left(\mathrm{Fe}_{5} \mathrm{Zn}_{21}\right)\end{array}$ & $\begin{array}{ll}\text { Base } & \text { centered } \\
\text { cubic }\end{array}$ & $1-2$ & $1-2$ & 77,46 & 54,48 & $\approx 71$ \\
\hline
\end{tabular}

$\mathrm{Fe}$ content decreases as a function of the distance towards the substrate-coating interface. The chronological order of the layers nucleation has been explained by Marder [2]. The zeta layer is first formed, after $5 \mathrm{~s}$, and is characterized by a columnar grain structure (columnar dendritic structure) with axes perpendicular to the surface. The columnar grain structure is well developed in sample A (Fig. 2-a) as well as in sample B (Fig. 2-b).

At the same time, solidification rate increases and fine grains appear in the top surface, as indicated by the arrow in Fig.2-b. Fine grains ensure the blocking of zinc liquid after its passage between grain boundaries and as a consequence, the crystallographic growth directions and the growth rate of grains change in zeta [12]. Generally, this residual solidified liquid has not the same composition as the liquid in the bath.

The zeta layer nucleation is immediately followed by delta-phase formation. Delta is also characterized by columnar grains. Zeta or delta phases were found to form a continuous layer at the lowest reaction times, i.e. after $5 \mathrm{~s}$. The third thin phase formed, after an incubation time of $30 \mathrm{~s}$, is gamma. The last eta-phase just forms at the surface of zeta when the plate is removed from the bath. It is composed of equiaxed grains.

After attack with 3\%Nital, some grains have been degraded (black contrast in Fig.3. Typically, they present the eutectic $\mathrm{Zn}-\mathrm{Pb}$ formed during the crystallization of the solid zinc; they can be enriched 
with alloying elements sensitive to the attack and especially with lead. But, Fig. 3 presents the eutectic in other structures (see the arrow and the circle). Grains are not totally degraded, the residual solute was rejected or absorbed during the solidification of the liquid zinc. This phenomenon is called the supercooling; the liquid zinc is "supercooled" under to its crystal homogeneous nucleation without solidifying.

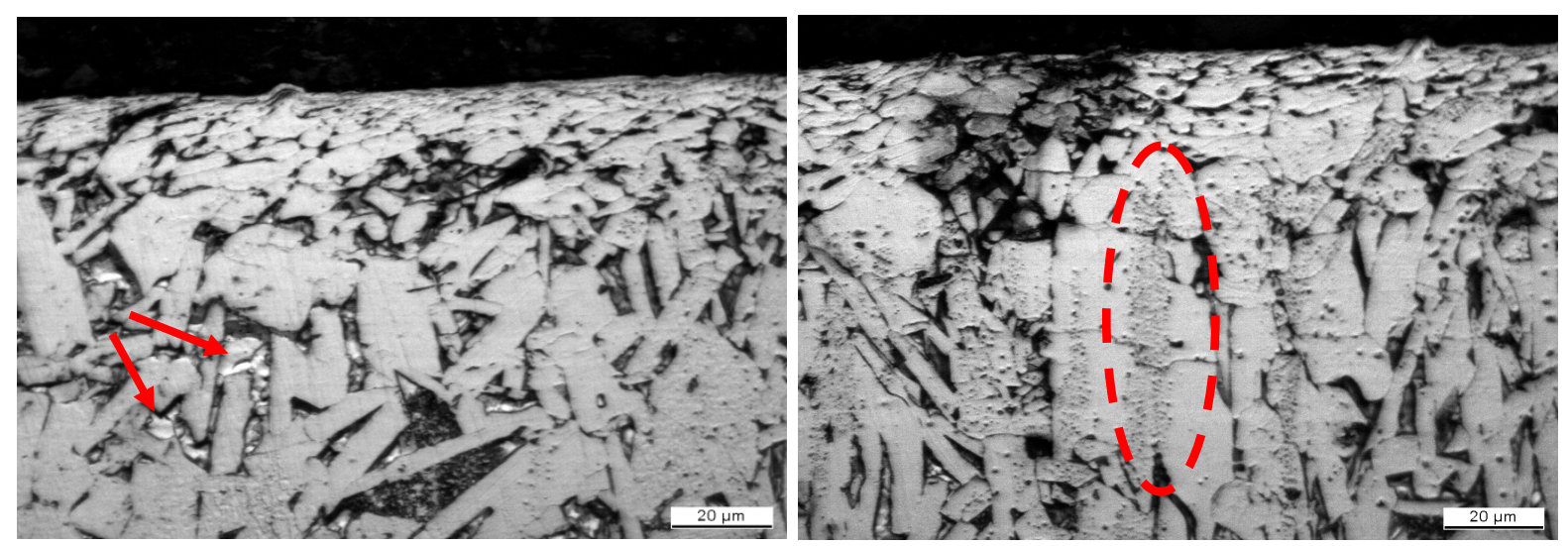

Fig. 3. Optical Micrographs of the eutectic $\mathrm{Zn}-\mathrm{Pb}$.

Evaluation of the residual stress using the hole drilling technique. The residual stress profiles were evaluated in the rolling direction (RD for $\sigma_{\mathrm{yy}}$ ) and the transverse direction (TD for $\sigma_{\mathrm{xx}}$ ), as shown in Fig. 4 (uncoated sample) and Fig.5 (HDG samples). Small increments $(20 \mu \mathrm{m})$ were performed to finely evaluate the stress in the zinc coating, while bigger increments of $100 \mu \mathrm{m}$ were selected for measurements in the substrate.

Let's focus on the residual stress profile in the rolling direction $\left(\sigma_{\mathrm{yy}}\right)$. In the uncoated sample (ref sample), the surface is affected by compressive stresses because of the effect of the rolling process (see Fig. 4). High tensile stresses can be observed in the A coating because of the holding during few minutes in the zinc bath. The maximum tensile residual stress level is observed at a subsurface depth of $50 \mu \mathrm{m}$ for both A and B coatings. Following the sign change at the interface, the substrates present a compressive stress. This trend is caused by the high temperature in the bath and by the cooling kinetics of zinc. At the interface, the residual stresses are respectively in A and B, $50 \mathrm{MPa}$ and $25 \mathrm{MPa}$, compared to $-150 \mathrm{MPa}$ before galvanizing. In the substrate, the compressive stresses are concentrated at a depth of $150 \mu \mathrm{m}$ to $250 \mu \mathrm{m}$ from the surface in A and B. The compressive stresses seem also to spread into a depth of $250 \mu \mathrm{m}$ in the reference sample, as for the sample B.

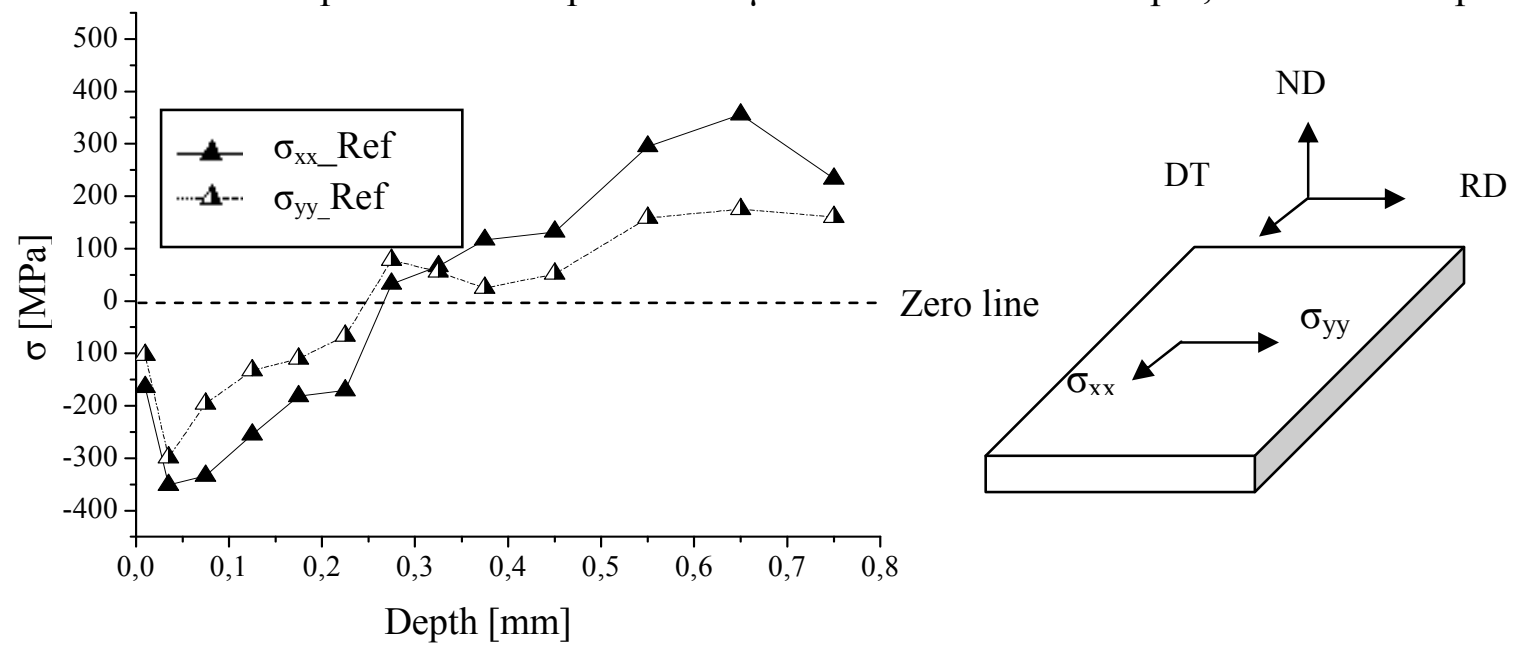

Fig. 4. The hole drilling evaluations of the residual stress along the transverse direction $\sigma_{\mathrm{xx}}$ and the rolling direction $\sigma_{\mathrm{yy}}$ of the uncoated sample (Ref sample). 

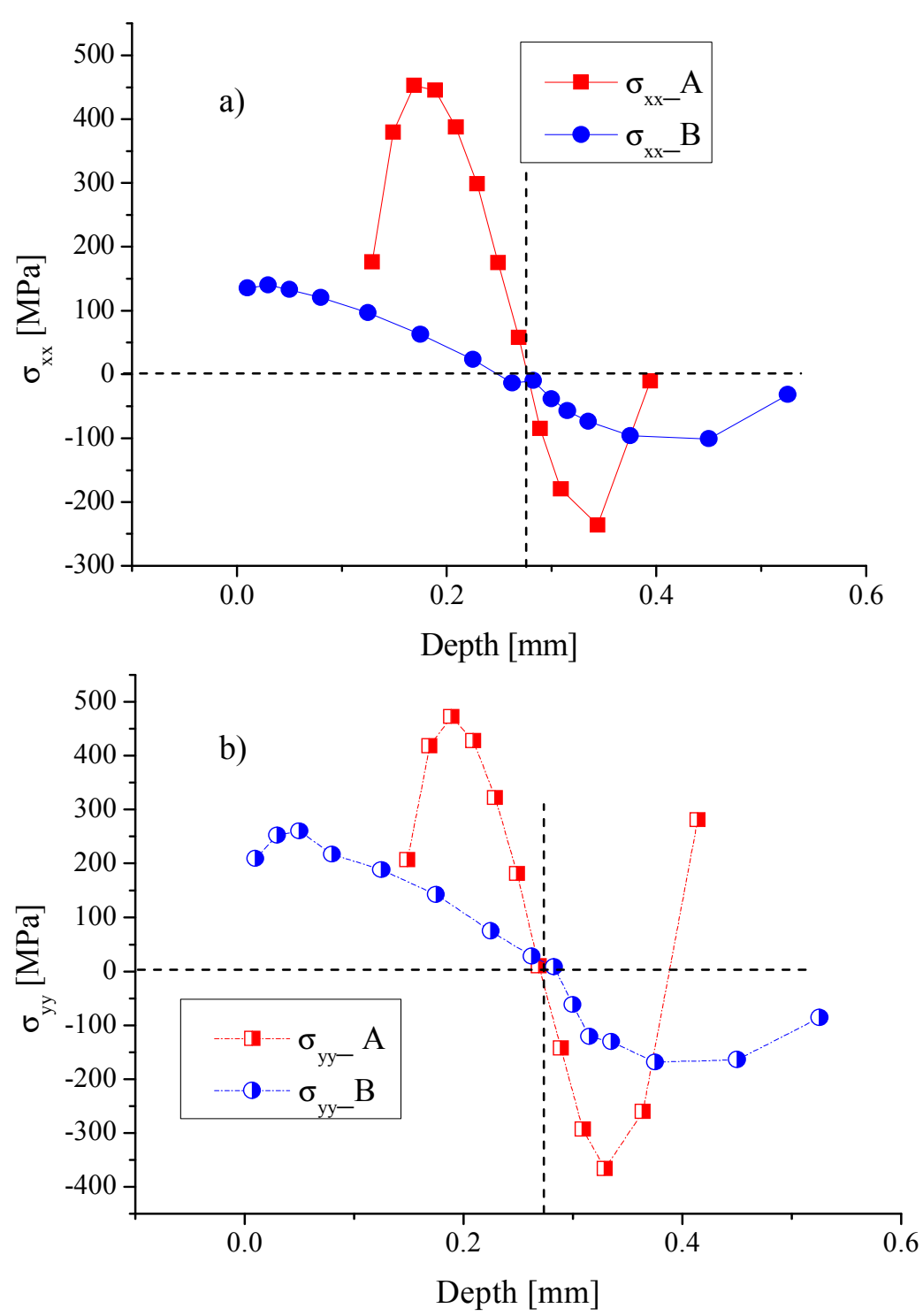

Fig. 5. The hole drilling evaluations of the residual stress along the transverse direction $\sigma_{\mathrm{xx}}(\mathrm{a})$ and the rolling direction $\sigma_{\mathrm{yy}}(\mathrm{b})$ of the HDG samples A and B.

\section{Summary}

In order to determine the influence of the holding time in the zinc bath on the stress profile as well as on the structure of the coating, an experimental investigation of two hot-dip galvanized coatings has been performed. We extract from this study the following findings:

1. The holding time increase from 3 and 10 minutes led to a thickness increase of the coating by about $50 \%$; from $145+/-14 \mu \mathrm{m}$ to $329+/-23 \mu \mathrm{m}$.

2. The growing of the zinc coating led to the formation of spangles in the top surface as well as dendrites.

3. Due to the difference of the thermal expansion coefficient between the substrate and the coating, as well as different mechanisms of the interdiffusion between layers, four intermetallic phases were identified.

4. Like for many crystals during their thermal cycling, the stress changes from the compressive state during the annealing process, to the tensile state during the cooling. The thicker B coating has a lower compressive stress level than the thinner A coating. It can be attributed to the time of immersion in the zinc bath. The residual stress level in the thicker B coating represents about $44 \%$ of the residual stress level in the A coating. 


\section{References}

[1] H. Guttman, P. Niessen, Reactivity of silicon steels in hot-dip galvanizing, Can. Metall. Q. 4 (1972) 609-615.

[2] A.R. Marder, The metallurgy of zinc-coated steel, Prog. Mater. Sci. 45 (2000) 191-271.

[3] G.K. Mandal, R. Balasubramaniam, S.P. Mehrotra, Theoretical Investigation of the Interfacial Reactions during Hot-Dip Galvanizing of Steel, Metall. Mater. Trans. A. 40 (2009) 637-645.

[4] C.E. Jordan, A.R. Marder, Fe - Zn phase formation in interstitial-free steels hot-dip galvanized at $450^{\circ}$ C: Part I 0.00 wt\% Al-Zn baths, J. Mater. Sci. 32 (1997) 5593-5602.

[5] K.-K. Lee, I.-H. Lee, C.-R. Lee, H.-K. Ahn, In-situ observation in a scanning electron microscope on the exfoliation behavior of galvannealed $\mathrm{Zn}-\mathrm{Fe}$ coating layers, Surf. Coatings Technol. 201 (2007) 6261-6266.

[6] J. Deng, M. Braun, Residual stress and microhardness of DLC multilayer coatings, Diam. Relat. Mater. 5 (1996) 478-482.

[7] A. Cavaleiro, A.P. Marques, J.V. Fernandes, N.J.M. Carvalho, J.T. De Hosson, Evolution of the microstructure, residual stresses, and mechanical properties of $\mathrm{W}-\mathrm{Si}-\mathrm{N}$ coatings after thermal annealing, J. Mater. Res. 20 (2005) 1356-1368.

[8] G. Reumont, J.B. Vogt, A. Iost, J. Foct, The effects of an Fe-Zn intermetallic-containing coating on the stress corrosion cracking behavior of a hot-dip galvanized steel, Surf. Coatings Technol. 139 (2001) 265-271.

[9] G. Montay, A. Cherouat, J. Lu, N. Baradel, L. Bianchi, Development of the high-precision incremental-step hole-drilling method for the study of residual stress in multi-layer materials: influence of temperature and substrate on $\mathrm{ZrO} 2-\mathrm{Y} 2 \mathrm{O} 38 \mathrm{wt} \%$ coatings, Surf. Coatings Technol. 155 (2002) 152-160.

[10] H. Asgari, M.R. Toroghinejad, M.A. Golozar, Effect of coating thickness on modifying the texture and corrosion performance of hot-dip galvanized coatings, Curr. Appl. Phys. 9 (2009) 59-66.

[11] M. Dutta, A. Mukhopadhyay, S. Chakrabarti, Effect of Galvanising Parameters on Spangle Size Investigated by Data Minining Technique, Iron Steel Inst. Japan, Tokyo, Jpn. 44 (2004) $129-138$.

[12] A.S.E. Semoroz, S. Henry, M. Rappaz, Application of the Phase-Field Method to the Solidification of Hot-Dipped Galvanized Coatings, Metall. Mater. Trans. A. 31 (2000) 487495.

[13] J. Strutzenberger, J. Faderl, Solidification and Spangle Formation of Hot-Dip-Galvanized Zinc Coatings, Metall. Mater. Trans. A. 29A (1998) 631-646. 